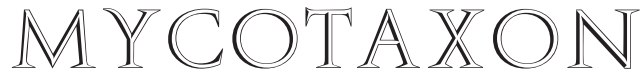

Volume 123, pp. 301-319

http://dx.doi.org/10.5248/123.301

January-March 2013

\title{
Three new Inocephalus species with cuboid basidiospores from New South Wales and Queensland, Australia
}

\author{
David L. Largent ${ }^{1 *}$, Sarah E. Bergemann ${ }^{2}$, Sandra E. Abell-Davis ${ }^{3}$, \\ Kerri L. Kluting ${ }^{2}$, \& Griffin A. Cummings ${ }^{2}$ \\ ${ }^{1}$ Biological Sciences, Humboldt State University 1 Harpst St, Arcata CA 95521 USA \\ ${ }^{2}$ Biology Department, Middle Tennessee State University \\ PO Box 60, Murfreesboro TN 37132 USA \\ ${ }^{3}$ School of Marine and Tropical Biology, Australian Tropical Herbarium and Centre for Tropical \\ Environmental \& Sustainability Science, James Cook University, \\ PO Box 6811, Cairns QLD 4870 AU \\ *Correspondence to: mrp@humboldt1.com
}

Aвstract - Three new Inocephalus species with cuboid spores are described from central New South Wales and northern Queensland, Australia. Inocephalus plicatus is diagnosed by its yellow pileus becoming plicate-striate and yellowish orange when mature, pungent odor, bitter taste, and pseudocystidia on all lamellar surfaces. Inocephalus hypipamee is differentiated by its brown umbonate pileus, white lamellae and stipe, obclavate cheilocystidia, subisodiametric basidiospores and clampless hyphae. Inocephalus parvisporus possesses small basidiospores and a Leptonia-like stature.

KEY WORDS - Basidiomycota, Entolomataceae, LSU, mtSSU, RPB2

\section{Introduction}

The Entolomataceae Kotl. \& Pouzar (Agaricomycetes, Basidiomycota) is a highly diverse euagaric family that includes more than 1500 species (Noordeloos \& Gates 2012). Three genera are typically recognized: Clitopilus (Fr. ex Rabenh.) P. Kumm., Rhodocybe Maire, and Entoloma (Fr.) P. Kumm. sensu lato. Species of Entolomataceae are difficult to diagnose to genus and the proposed concepts of classification typically recognize either 13 subgenera within a single genus Entoloma sensu lato (Noordeloos 1992, 2004) or 13 genera including Entoloma sensu stricto (Largent 1994). Several phylogenetic studies were recently undertaken to produce a framework for placing species into genera or subgenera (Co-David et al. 2009, Baroni et al. 2011, Baroni \& Matheny 2011). Although these studies have provided an important context for 
framing ongoing debates of evolutionary relationships among species, most of the monophyletic subgroupings lack statistical support.

Without a stable system of classification, newly described species of Entolomataceae are classified into genera or subgenera using a combination of morphological characters. Here, we follow the concept of Largent (1994) and Baroni \& Halling (2000) for Inocephalus (Noordel.) P.D. Orton based on these morphological features: a mycenoid or collybioid habit, a non-glabrous innately fibrillose to squamulose pileus, an entangled pileipellis often nearly a trichoderm on the disc, a pileipellis that intergrades imperceptively with the pileal trama, abundant oleiferous hyphae and lipoid bodies, cheilocystidia and/ or pseudocystidia, and basidiospores with 4-7 distinct angles, some of which are cuboid.

Cuboid basidiospores, unique to the Entolomataceae, have interested investigators ever since Entoloma virescens (Sacc.) E. Horak ex Courtec. was described from the Bonin Islands in 1857 (Horak 1976). Their history, distribution, systematics, taxonomic significance, and development within the Entolomataceae have been thoroughly reviewed (Baroni \& Halling 2000; Eyssartier et al. 2001; Horak 1976, 1977; Pegler \& Young 1978; Romagnesi 1941). In Australia, two species with a cuboid spore-type have been reported: Inocephalus virescens (Sacc.) Largent \& Abell-Davis ( $=$ E. virescens) (Young 2005, Largent \& Abell-Davis 2011) and E. procerum G. Stev. (May \& Wood 1997, Ratkowsky \& Gates 2002, Noordeloos \& Gates 2012). Herein, we describe three new species with cuboid basidiospores: Inocephalus plicatus, I. hypipamee, and I. parvisporus.

\section{Materials \& methods}

\section{Macromorphological and micromorphological features}

Specimens were collected during February-April 2009-11 from various localities within the Wet Tropics Bioregion throughout northeastern Queensland and during April 2010-11 from temperate rainforests in central New South Wales. General and technical names indicated by quotations marks in the descriptions are from the Colour Diagrams Section of Kornerup \& Wanscher (1978: 196-225).

The factors determined from mathematical analyses in the descriptions include: the arithmetic means $(x)$ of spore lengths and spore widths \pm standard deviation in $\mathrm{n}$ objects measured; the quotient of spore length by spore width (E) indicated as a range variation in $n$ objects measured; the mean of E-values $(\mathrm{Q}) \pm$ standard deviations. The sample size (n) is equal to the total number of microscopic structures measured $(x)$ and the number of basidiomata studied $(\mathrm{y})$ and is given in the format $\mathrm{n}=\mathrm{x} / \mathrm{y}$. The $\mathrm{Q}$ values are used to define general basidiospore shape with the following types recognized: isodiametric with $\mathrm{Q}=1.0-1.15$; subisodiametric with $\mathrm{Q}=1.16-1.27$; heterodiametric $\mathrm{Q}>1.27$ (Largent 1994). Details of macroscopic and microscopic features and measurements were described in a previous paper (Largent \& Abell-Davis 2011). 
All collections for New South Wales cited in the 'Additional collections examined' were deposited in The Plant Pathology Herbarium, Orange Agricultural Institute (DAR), while collections made in Queensland were split with duplicates deposited in the Australian Tropical Herbarium (CNS) and The Queensland Herbarium (BRI). All holotype and isotype collections are deposited in the herbaria designated using acronyms from Thiers (2012).

\section{DNA sequences}

The details of protocols for DNA extractions, PCR amplification of partial sequences of the mitochondrial small subunit of the ribosomal DNA (mtSSU), variable domains (D1, D2) of the nuclear large subunit (LSU) and sequencing protocols are described in previous publications (Largent et al. 2011a, b). PCR primers used for amplification of the second largest subunit of the RNA polymerase gene (RPB2) from Inocephalus were performed with either of one of two forward primers, rpb2-EntF1 ( $5^{\prime}$ to $3^{\prime}$ - GAA GGT CAA GCT TGY GGT C) or rpb2-EntF2 ( $5^{\prime}$ to $3^{\prime}$ - GAA GGY CAR GCY TGY GGT C) or with either one of two reverse primers, rpb2-EntR3 (TGG ATY TCR CAR TGC GTC CA) or rpb2-EntR5 (TGR ATY TCR CAR TGG GTC CA). PCR amplifications of the RPB2 gene were performed in $25 \mu \mathrm{L}$ reactions containing $1 \times$ GoTaq Flexi Buffer (Promega, Madison WI USA), $2 \mathrm{mM} \mathrm{MgCl}_{2}, 0.2 \mathrm{mM}$ dNTPs, $500 \mathrm{nM}$ forward and reverse primers, $0.2 \mathrm{mg} / \mathrm{mL}$ bovine serum albumin, $1 \mathrm{M}$ betaine, $0.025 \mathrm{U}$ Taq polymerase, and 1-3 $\mu \mathrm{L}$ of undiluted template DNA. PCR cycling conditions were as follows: $95^{\circ} \mathrm{C}$ for $2 \mathrm{~min}$, followed by 40 cycles of $95^{\circ} \mathrm{C}$ for $30 \mathrm{sec}, 52^{\circ} \mathrm{C}$ or $54^{\circ} \mathrm{C}$ or $56^{\circ} \mathrm{C}$ for $1 \mathrm{~min}$, and $72^{\circ} \mathrm{C}$ for $1 \mathrm{~min}$, followed by a final extension of $72^{\circ} \mathrm{C}$ for $10 \mathrm{~min}$. Forward and reverse sequences for each locus were generated on an Applied Biosystems 3130xl Genetic Analyzer at Middle Tennessee State University following the protocols outlined in Largent et al. (2011a, b).

\section{Results}

We obtained partial sequences for the mitochondrial small subunit rRNA gene (mtSSU), nuclear large subunit (LSU), and the second largest RPB2 subunit for a subset of collections of I. plicatus and I. hypipamee (TABLE 1). Notes on the morphology of the basidiomata exist for seven I. plicatus collections and

TABLE 1. Inocephalus specimens included in this study.

\begin{tabular}{llccc}
\hline Species & Collection Identifier & \multicolumn{2}{c}{ GenBAnK Accession Numbers } & RPB2 \\
\hline I. hypipamee & DL Largent 9649 & JQ624602 & JQ624607 & - \\
& DL Largent 9981 & JQ624603 & JQ624608 & - \\
& DL Largent 10071 & JQ624604 & JQ624609 & JQ624616 \\
I. plicatus & DL Largent 9691 & JQ624605 & JQ624610 & JQ624617 \\
& DL Largent 9885 & - & JQ624611 & JQ624618 \\
& DL Largent 10083 & - & JQ624612 & JQ624619 \\
& DL Largent 10091 & - & JQ624613 & JQ624620 \\
& DL Largent 10096 & - & - & JQ624621 \\
& DL Largent 10124 & - & JQ624614 & JQ624622 \\
& DL Largent 10216 & JQ624606 & JQ624615 & JQ624623 \\
\hline
\end{tabular}


the three I. hypipamee collections with sequences. These sequences were used to formulate the descriptions and develop the diagnostic characters for both species.

Sequences of I. parvisporus were omitted after several attempts to sequence PCR products from the three loci failed.

\section{Taxonomy}

Inocephalus plicatus Largent, sp. nov.

Plates 1-2

\section{MrcoBank MB 564924}

Differs from Inocephalus pseudomurrayi by its larger basidiomata, yellow pileus maturing to plicate-striate and yellowish orange, pungent odor, latently unpleasant taste, and pseudocystidia on lamellar edge and face.

Type - Australia, New South Wales, central Hunter District, Strickland State Forest,

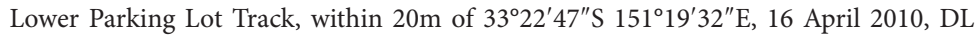
Largent 9885 (holotype DAR).

Етумодоgy - from the Latin plicatus referring to the pleated (plicate) pileal surface.

Pileus $17-40 \mathrm{~mm}$ broad, 5-8 $\mathrm{mm}$ high, conic to convex at first, becoming broadly convex to broadly campanulate with maturity, with a rounded to mammillate umbo, glabrous or atomate to the eye, or under $4 \times$ or $20 \times$ magnification, minutely appressed-fibrillose except for the minutely roughened center, dull, opaque, not hygrophanous, at first even but with maturity quickly becoming striate and then plicate-striate from the margin to near the center, at first pale yellow to light yellow; (2-3A5, 3-4A4), often with a slightly darker center (3A6, 4A5-4B6, 4A5-6) becoming greyish yellow to greyish orange when picked, drying or fading (4-5A-B3-4, 5B4-5, 7E-F8); margin decurved at all times, entire and with age becoming broadly lobed and crenulate and finally eroded. TASTE mild at first and then latently bitter to unpleasant. ODOR mild and then pungent. LAMELlAE 6-20 mm long, adnexed, subdistant, moderately broad (3-8 $\mathrm{mm}$ ), pale yellow at first (3A3) becoming orange white to near pale orange with spore maturity (4-5A2-3, 4A3-4, 5A3-4, 5A5-6); margin smooth and concolorous to the eye, cystidiate under $4 \times$ or $20 \times$ magnification; 3 lamellulae ( 2 medium short; 1 medium long) in two layers between the lamellae. STIPE $35-85 \mathrm{~mm}$ long, 3-5 $\mathrm{mm}$ broad at apex, $3.5-8 \mathrm{~mm}$ broad at base, at times flattened and longitudinally grooved and then $3 \times 4.5 \mathrm{~mm}$ broad at apex, $4 \times 5 \mathrm{~mm}$ broad at base, typically clavate, rarely twisted, glabrous except minutely roughened to pruinose at the apex, pale yellow to light yellow (2A4 to $3-4 \mathrm{~A} 2-4)$ darkening to pale orange $(5 \mathrm{~A} 3-5,5 \mathrm{~B} 4)$ and/or discoloring to light brown $(4-5 \mathrm{D} 7,5 \mathrm{D} 7)$ stuffed at first, becoming hollow, sturdy; basal tomentum scarce to absent. BRUISING REACTIONS pileus frequently staining brownish orange (6C8) to dark brown with a reddish orange tint. 
Inocephalus spp. nov. (Australia) ... 305

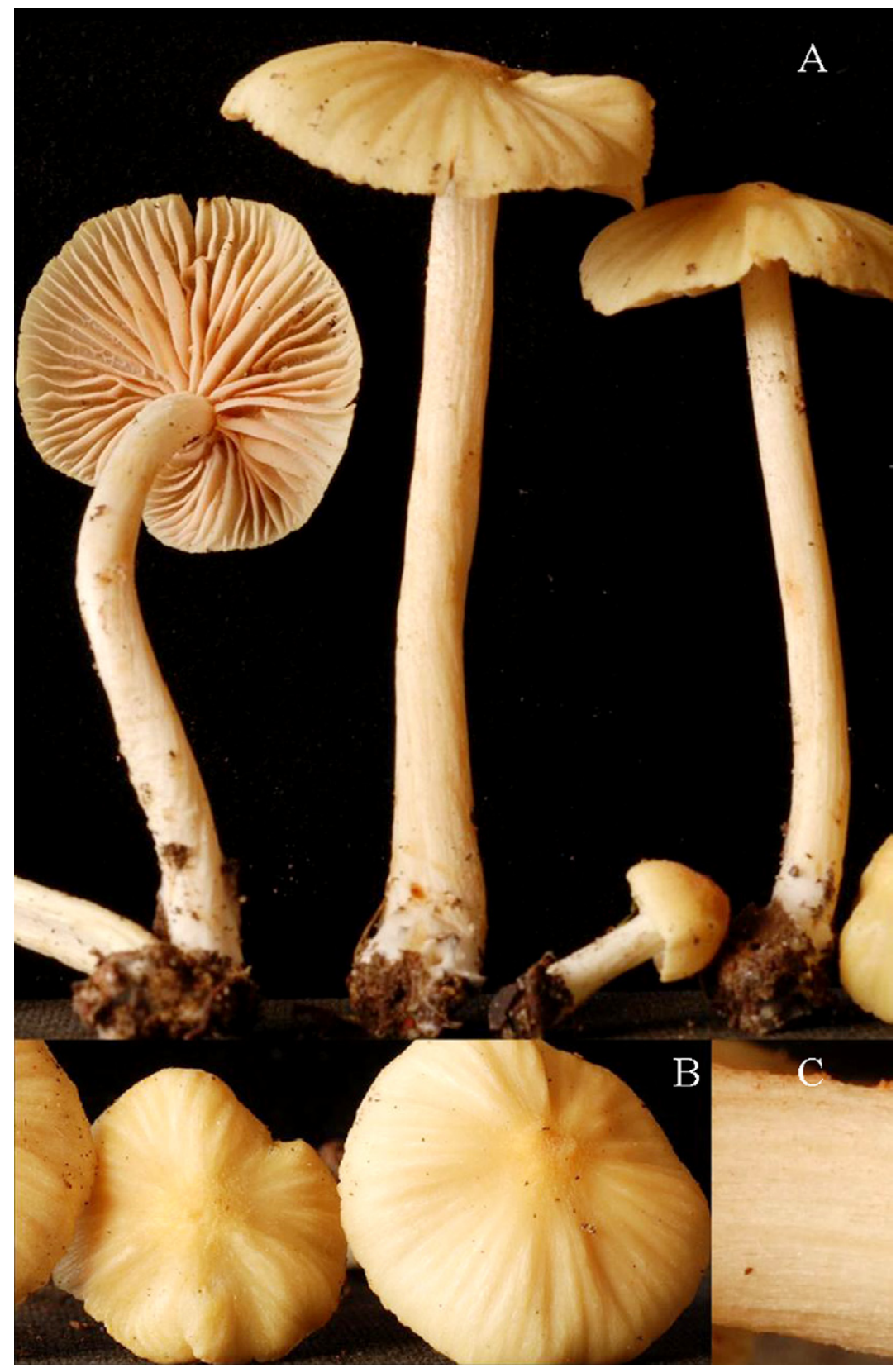

PLATE 1. Inocephalus plicatus (DLL 10091). A: Basidiomata (2.5×); B: Pileus surface (2×); C: Stipe apex $(8 \times)$. 
BASIDIOSPORES in profile view versiform, cuboid, rhomboid, and at times rectangular, often with one angle enlarged, rarely 3 -angled and then trapezoidlike, sometimes 5-angled, isodiametric to heterodiametric in dorsal or ventral view, 4-5-angled and isodiametric in polar view, 7.7-11.9 $\times 6.6-10.4 \mu \mathrm{m}$ $(x=9.6 \pm 0.9 \times 8.5 \pm 0.8 \mu \mathrm{m} ; \mathrm{E}=1.0-1.4 ; \mathrm{Q}=1.2 \pm 0.1$ (subisodiametric); $\mathrm{n}=169 / 7)$. BAsidia typically long and clavate, tapered to the base, the base typically enlarged, $40.5-73.2 \times 9.5-18.1 \mu \mathrm{m}(x=55.5 \pm 6.9 \times 12.4 \pm 1.5 \mu \mathrm{m}$; $\mathrm{E}=3.2-7.4 ; \mathrm{Q}=4.5 \pm 0.8 ; \mathrm{n}=53 / 6) ; 4$-sterigmate, sterigma 3.7-6.2 $\mu \mathrm{m}$; base of basidium 1.9-5.2 $\mu \mathrm{m}$. АвоRTED Basidia absent. Cheilocystidia typically forming a sterile layer, at times scattered, colorless to opaque, clavate to cylindroclavate eventually becoming strangulated to somewhat contorted, tapering to the apex, $66.5-144.4 \times 4.8-12.2 \mu \mathrm{m}(\mathrm{n}=14 / 2)$. Pseudocystidia scattered to abundant on the lamellar edge and face, filled with granular refractive material yellowish in $3 \% \mathrm{KOH}$, cylindro-clavate, typically contorted, $21.8-87.3 \times 3.2-9.1$ $\mu \mathrm{m}(\mathrm{n}=29 / 4)$. HYPHAE OF THE LAMELLAR TRAMA subparallel and quite long, 136-1119 × 3.7-22.7 $\mu \mathrm{m}(\mathrm{n}=37 / 5)$. Pileipellis an entangled, semi-erect layer of hyphae, entirely erect at first, with maturity remaining so in the center but a cutis elsewhere. Pileocystidia cylindro-clavate, 66.5-144.4 $\times 4.9-21.5 \mu \mathrm{m}$ ( $n=22 / 3$ ). Hyphae of the pileal trama quite long, 43.6-507.0 $\times 6.1-26.9$ $\mu \mathrm{m}(\mathrm{n}=11 / 3)$. Stipitipellis at the apex an entangled layer of semi-erect caulocystidia. Caulocystidia cylindro-clavate, similar to the pileocystidia, 37.6-167.6 × 4.6-11.2 $\mu \mathrm{m}(\mathrm{n}=30 / 5)$. Hy PHAE OF THE STIPE TRAMA not studied. LIPOID GLOBULES abundant in all tissues and obscuring all microscopic features when viewed in 3\% $\mathrm{KOH}$. Oleiferous hyphaE abundant in the lamellar trama, in the subhymenium, and the pileal trama. BRILLIANT GRANULES absent. Pigmentation cytoplasmic and yellowish in the hyphae of the pileipellis and stipitipellis in 3\% KOH. Clamp CONNECTIONs present in all tissues.

ECOLOGY AND DISTRIBUTION - Solitary, scattered, or gregarious in sandy organic rich soil, in deep leaf humus or protected by logs and woody debris, warm temperate gallery rainforest near Ceratopetalum apetalum D. Don, Backhousia myrtifolia Hook., and Syncarpia glomulifera (Sm.) Nied. (Strickland State Forest, New South Wales). In other localities, found in warm, temperate,

Plate 2. Inocephalus plicatus. A: 4-angled basidiospores (2500×), rectangular in profile view (left), nearly square in dorsi-ventral view (center), and becoming rhomboid in profile view (right) (DLL 10091); B: Pseudocystidium to left of basidium (2000×) (SSF 12); C: Stipitipellis with cylindroclavate caulocystidia (50×) (SSF 12); D: Pileipellis with clavate to cylindro-clavate pileocystidia (125×) (SSF 12); E: Pseudocystidium from lamellar face (450×) (DLL 10091); F: Strangulated to somewhat contorted cheilocystidia, 2-sterigmate basidium (lower left corner), and oleiferous hyphae (darker) (350×) (DLL 9885, holotype); G: Section of lamellae with abundant oleiferous hyphae, lipoid globules, and showing origin of pseudocystidium (100×) (DLL 9885, holotype). 
Inocephalus spp. nov. (Australia) ... 307

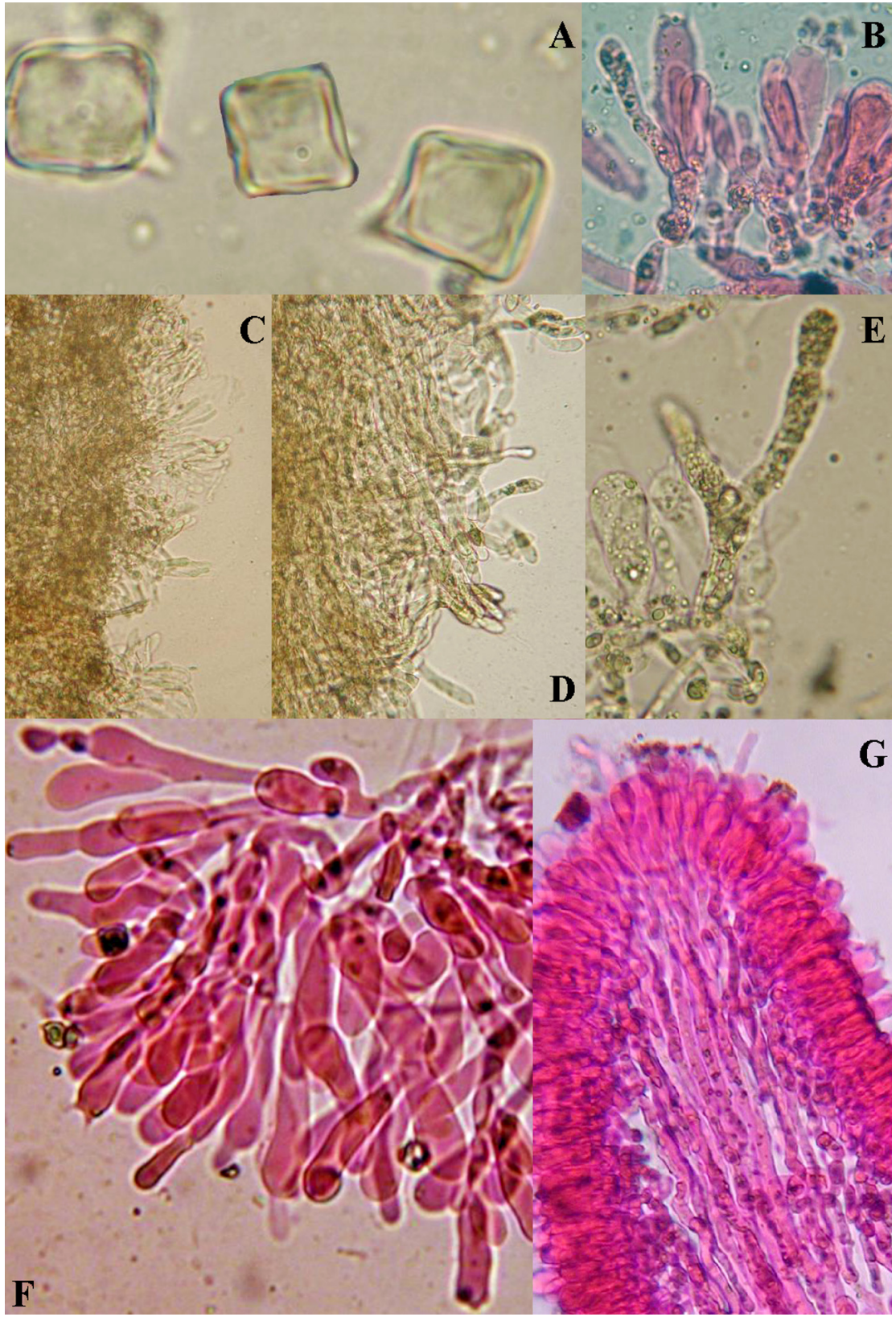


subtropical gallery rainforests (New South Wales) and wet tropical rainforests (northeastern Queensland).

\begin{abstract}
Additional collections examined - AUSTRAlia. New South Wales, central Hunter District, Barrington Tops National Park, Jerusalem Creek Track, 25 April 2010,

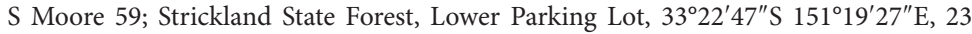

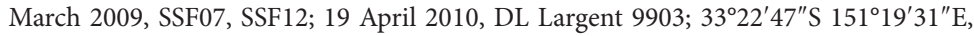

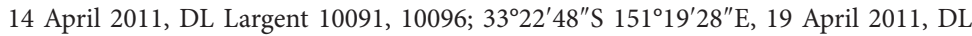
Largent 10124; 33⒉ $2^{\prime} 47^{\prime \prime} \mathrm{S} 151^{\circ} 19^{\prime} 33^{\prime \prime} \mathrm{E}, 28$ April 2011, DL Largent 10165; 33⒉ $22^{\prime} 47^{\prime \prime} \mathrm{S}$ $151^{\circ} 19^{\prime} 29^{\prime \prime}$ E, 7 May 2011, DL Largent 10216; Watagans National Park, Boardinghouse Dam Area, 32 59'56"S 15124'19"E, 12 April 2011, DL Largent 10083. QueENSLAND,

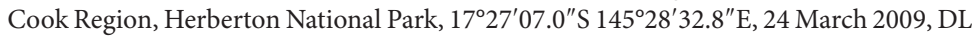
Largent 9691; $17^{\circ} 27^{\prime} 14.8^{\prime \prime} \mathrm{S} 146^{\circ} 28^{\prime} 34.2^{\prime \prime} \mathrm{E}, 16$ March 2010, DL Largent 9786; Mt. Lewis National Park, $16^{\circ} 16^{\prime} 10.1^{\prime \prime} \mathrm{S} 147^{\circ} 16^{\prime} 11.0^{\prime \prime} \mathrm{E}, 20$ March 2010, DL Largent 9803; Mossman Gorge National Park, 16 $28^{\prime} 16.9^{\prime \prime} \mathrm{S} 145^{\circ} 19^{\prime} 51.6^{\prime \prime} \mathrm{E}, 25$ February 2010, DL Largent 9741, 9742.
\end{abstract}

Comments - Inocephalus plicatus is distinguished from other Inocephalus taxa by the following set of diagnostic features: yellow basidiomata when young with a pileus that is greyish yellow to greyish orange, plicate-striate and mammillate umbonate at maturity and that stains brownish orange or darker with handling; pileus tissue producing a latently bitter to unpleasant taste and a latently pungent odor; mostly cuboid or rhomboid basidiospores averaging $\leq 10 \times 9.0 \mu \mathrm{m}$; contorted and refractive pseudocystidia on lamellar face and edge as well as abundant, contorted or strangulated and opaque cheilocystidia; a pruinose stipe apex composed of cylindro-clavate caulocystidia; abundant oleiferous hyphae in the lamellar and pileal trama; and abundant clamps.

Morphologically, I. plicatus resembles Entoloma pseudomurrayi Eyssart. et al., E. cuspidatum Sacc., and I. murrayi (Berk. \& M.A. Curtis) Rutter \& Watling (三E. murrayi (Berk. \& M.A. Curtis) Sacc.).

Entoloma pseudomurrayi from New Caledonia shares many similar morphological features with I. plicatus but is differentiated by the smaller basidiomata, the citrine yellow, non-plicate, non-staining pileus that does not darken to greyish yellow or greyish orange, the mild odor and taste, the lanceolate to fusiform and moniliform cheilocystidia, and pseudocystidia found only on the lamellar edge (Eyssartier et al. 2010).

Entoloma cuspidatum ( $\equiv$ Agaricus cuspidatus Peck, nom. illegit., non A. cuspidatus Bolton) is morphologically differentiated from I. plicatus by its conic to campanulate, cuspidate, pale yellow, non-striate pileus and basidiospores measuring 9-13 × 8-12 (-12.5) $\mu \mathrm{m}$. The basionym of Inocephalus murrayi ( Agaricus murrayi Berk. \& M.A. Curtis) is morphologically differentiated from I. plicatus by its non-plicate pileus that turns reddish brown on drying and basidiospores measuring 9-11 $\times 9.5-11 \mu \mathrm{m}$. 


\section{The synonomy of Entoloma cuspidatum and Inocephalus murrayi}

Entoloma cuspidatum is considered a synonym of $I$. murrayi by Baroni \& Halling (2000) and of E. murrayi by Hesler (1963, 1967), Horak (1976, 1980), and Singer (1942). This synonymy should be re-evaluated because of the following discrepancies.

Peck's (1872: 64-65) protologue description of A. cuspidatus differs from that of A. murrayi (Berkeley \& Curtis 1859: 289). Agaricus cuspidatus has a conic to campanulate, non-striate pileus pale yellow throughout, an elongated papilla or cusp, and basidiospores $1 / 2000$ inch $(=12.7 \mu \mathrm{m})$ in diameter. Agaricus murrayi has a convex regularly striate pileus that is straw yellow turning rich red brown when dry and basidiospores $1 / 2500$ inch $(=10.16 \mu \mathrm{m})$ in diameter. Using these features, Peck considered the two species related but different (Noordeloos 2008: 96).

Studies of the holotype collections indicate the basidiospores of A. murrayi measure 9-11 × 9.5-11 $\mu \mathrm{m}$ (Singer 1942) and are indeed a little smaller than those measured for A. cuspidatus Peck (9-13 $\times 8-12 \mu \mathrm{m}$, Hesler 1963; 11-13.5 $(-14) \times(9.5-)$ 10-11.5 (-12.5) $\mu \mathrm{m}$, Baroni pers. comm.; 9-11.7 $\times 8.0-11.7 \mu \mathrm{m}$, Noordeloos 2008).

\section{Australasian species morphologically similar to Inocephalus plicatus}

Several other species from Australasia morphologically resemble I. plicatus in yellow coloration and cuboid basidiospores. Entoloma pallidoflavum (Henn. \& E. Nyman) E. Horak from Java, Borneo, and New Guinea is differentiated by the larger pileus $(30-80 \mathrm{~mm}$ ) and stipe ( $\leq 130 \mathrm{~mm}$ long), an indistinctive or radish-like odor, and coarsely dentate-serrate lamellae. Entoloma albogracile E. Horak from Papua New Guinea and E. avilanum (Dennis) E. Horak from Venezuela have tetrahedral-cuboid basidiospores. Entoloma gracilius E. Horak from Papua New Guinea has smaller basidiospores (5.5-7.0 $\mu$; Horak 1976). Inocephalus luteus (Peck) T.J. Baroni ( E Entoloma luteum Peck) from eastern North America is morphologically differentiated by the smoky yellow, at times greenish yellow, distinctly fibrillose pileus as typified by the protologue description and illustration (Baroni, pers. comm.).

Inocephalus hypipamee Largent, sp. nov.

Plates 3-4

MycoBAnk MB 564925

Differs from Entoloma flavotinctum by its larger basidiomata, non-hygrophanous pileus, white then yellowish white stipe, white context, and larger basidiospores.

TyPe - Australia. Queensland, Cook Region, Mt. Hypipamee National Park, within $20 \mathrm{~m}$ of $17^{\circ} 25^{\prime} 35.2^{\prime \prime} \mathrm{S} 145^{\circ} 29^{\prime} 14.6^{\prime \prime} \mathrm{E}, 25$ March 2011, DL Largent 10071 (holotype BRI, isotype CNS).

EтумоLоgy - from the Australian Aborigine hypipamee, referring to the frequent occurrence of this species in Mt. Hypipamee National Park. 
Pileus 9-70 mm broad, 4-23 mm high, when young narrowly parabolic, conic, or convex, entirely and densely matted-tomentose to tomentulose, quickly developing an acute to broad umbo; upon expansion and maturity becoming broadly conic, broadly convex, campanulate-convex, or campanulate, always remaining densely matted-fibrillose to tomentulose on the apex and umbo but becoming densely appressed-squamulose elsewhere, eventually becoming matted-fibrillose-squamulose and somewhat rimulose at or near the margin, overly mature specimens becoming fibrillose and rimose everywhere except on or near the umbo; when very young or in basidiomata protected by overhanging logs, the fibrils, hairs, and tomentum greyish orange to brownish orange (6B-C2-3) on and around the umbo and white to orange white (6A-B12) elsewhere, upon exposure and in young exposed basidiomata brown to dark brown (6F4-5) everywhere, in maturing specimens remaining so on or near the umbo, elsewhere fading to a lighter brown (between 5E3-4 and 6E3-4) then becoming brownish orange (between 5C-D3-4 and 6C-D3-4) from the margin to the umbo, in very old specimens the fibrils become rimose and thus the orange white to greyish orange (6A-B2-3) background color becomes visible; surface opaque (not hygrophanous, not translucent-striate); margin decurved and entire, eventually becoming plane or uplifted, fibrillose, crenulate, and eroded; context up to $1.25 \mathrm{~mm}$ above the stipe, $<1 \mathrm{~mm}$ midway to margin, and nearly non-existent at the margin, white to off-white. TASTE mild becoming, at most, latently slightly unpleasant. ODOR mild or indistinct. LAMELLAE 6-32 mm long, 1-9 mm deep, when young yellowish white (3A2) then very pale yellow (4A3) and with spore maturity between orange white and pale orange (5A2 or $5 \mathrm{~A} 3$ ), narrowly adnate or broadly adnexed at all times but often with a decurrent tooth, at first close to crowded and narrow then subdistant and moderately broad to sigmoid; margin smooth and concolorous to the eye but under the dissecting microscope abundantly cystidiate; 3 lamellulae/2 lamellae. STIPE 18-68 mm long, 1-7 $\mathrm{mm}$ broad at apex, 2-8 $\mathrm{mm}$ broad at base, equal in young specimens, but with maturity typically enlarged at the base, white or off-white (3A2) becoming yellowish white (4A2) with age, to the eye glabrous except pruinose at the apex, under the dissecting microscope suggestively appressed-fibrillose, hollow but solid or sturdy; basal tomentum scarce to absent; context unchanging when cut. BRUISING REACTIONS slightly brownish on the stipe.

BASIDIOSPORES in profile view typically cuboid or rectangular, sometimes 5-angled, isodiametric to heterodiametric in profile and dorsiventral views, isodiametric in polar view, 7.1-10.4 ×6.2-8.6 $\mu \mathrm{m}(x=8.8 \pm 0.8 \times 7.4 \pm 0.6 \mu \mathrm{m}$; $\mathrm{E}=0.9-1.4 ; \mathrm{Q}=1.2 \pm 0.1$ (subisodiametric); $\mathrm{n}=58 / 2$ ). BAsIdiA mostly clavate, typically long and tapered to the base, $37.9-49.3 \times 9.0-12.0 \mu \mathrm{m}(x=43.2 \pm 3.24 \times$ $10.1 \pm 0.79 ; \mathrm{E}=3.4-5.3 ; \mathrm{Q}=4.1 \pm 0.5 ; \mathrm{n}=20 / 2) ; 4$-sterigmate, sterigma 2.5-4.1 


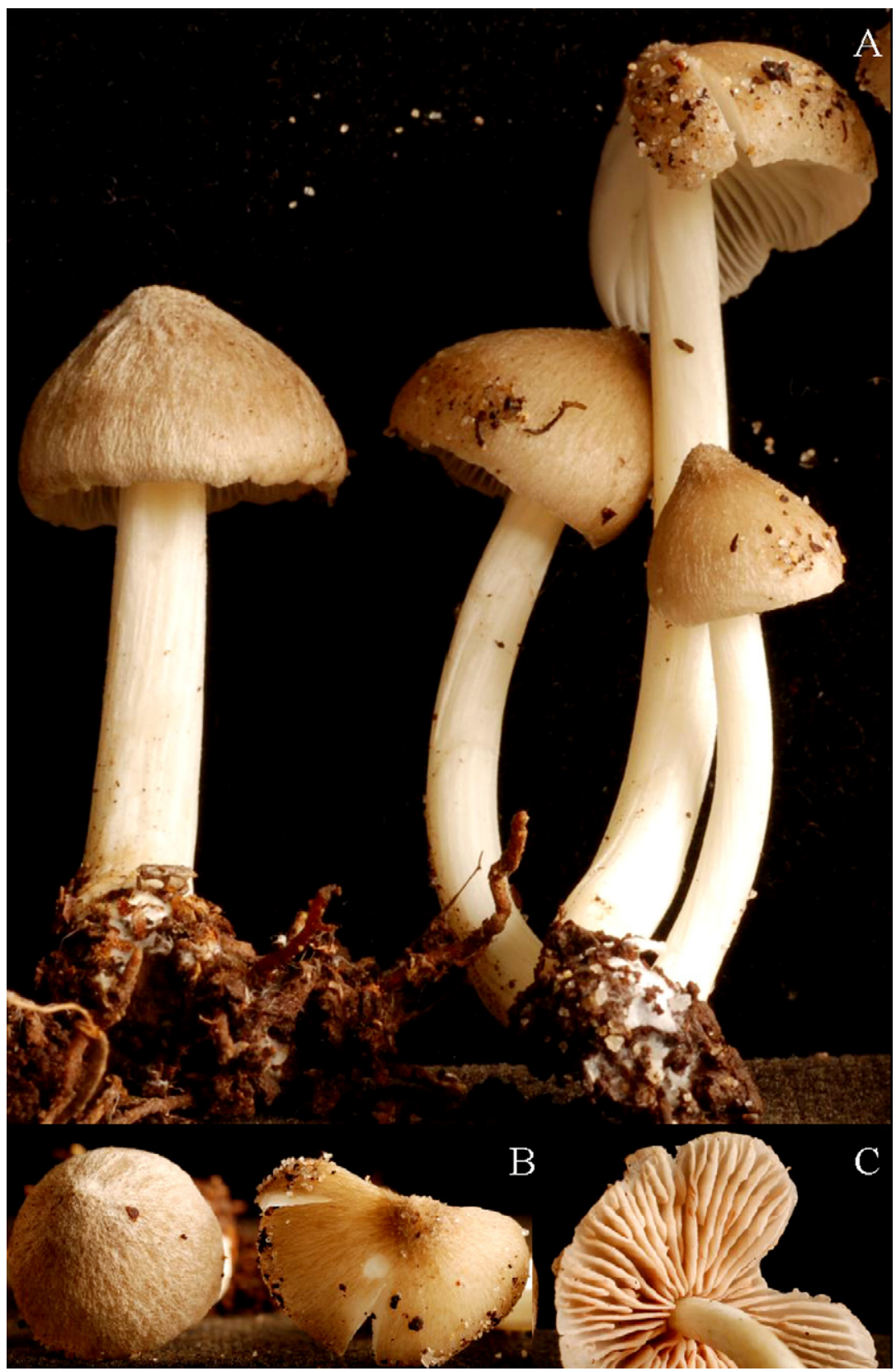

Plate 3. Inocephalus hypipamee. A: Basidiomata stature (2×) (DLL 10035); B: Pileus surface, young (left), and mature (right) (2×) (DLL 10035); C: Lamellae and lamellulae (2×) (DLL 9999). 
$\mu \mathrm{m}$ long; base of basidia 3.5-5.4 $\mu \mathrm{m}$ wide. ABORTED BASIDIA rare to scattered, embedded in the hymenium. Hymenial CYSTIDia abundant and obvious, present as Pseudocystidia, typically filled with a yellowish oily material, becoming reddish brown in $3 \% \mathrm{KOH}$, those on the lamellar edge clavate to obclavate or fusoid, $38.3-46.2 \times 4.4-12.8 \mu \mathrm{m}(\mathrm{n}=7 / 1)$; those on the lamellar face similar in shape but longer than those on the lamellar edge, originating from the outer layers of the lamellar trama, 47.6-106.5 $\times 5.0-19.5 \mu \mathrm{m}(x=$ $76.6 \pm 18.4 \times 12.7 \pm 3.7 \mu \mathrm{m} ; \mathrm{E}=4.3-9.6 ; \mathrm{Q}=6.3 \pm 1.6 ; \mathrm{n}=14 / 2)$. НYPHAE OF THE LAMELLAR TRAMA subparallel, moderately long to long, 107.7-582.3 $\times$ 4.2-14.7 $\mu \mathrm{m}(\mathrm{n}=8 / 2)$. Pileipellis in fresh specimens composed of semi-erect and laterally agglutinated hyphae with cylindro-clavate to clavate terminal cells, in dried specimens also composed of entangled and laterally agglutinated hyphae but with cylindro-clavate terminal cells often collapsed on top of clavate ones. Pileocystidia cylindro-clavate or clavate 30.5-51.6 $\times 5.9-14.6 \mu \mathrm{m}$ $(n=6 / 1)$. HyPHAE OF THE PILEAL TRAMA above the lamellar trama 55.0-173.8 $\times 9.8-15.0 \mu \mathrm{m}(\mathrm{n}=9 / 1)$. STIPITIPELLIS a cutis except at the apex with clusters of basidioles or small clavate caulocystidia. CAULOCYsTIDIA 31.0-41.2 $\times 7.1-10.7$ $\mu \mathrm{m}(\mathrm{n}=3 / 1)$. Hyphae of THE stipe trama parallel, 55.0-188.0 $\times 9.8-26.3$ $\mu \mathrm{m}(\mathrm{n}=9 / 1)$. LiPOID GLOBULES abundant in all tissues, often obscuring other microscopic features. Oleiferous hyPHAE abundant throughout the lamellar and pileal trama. Brilliant granules absent. Pigmentation composed of abundant dark brown, cytoplasmic plaque-like areas in the hyphae of the pileipellis, absent elsewhere. Clamp conneCtions absent in all tissues.

ECOLOGY AND DISTRIBUTION - Typically solitary but at times gregarious with clusters of 2-4 basidiomata, in granitic soil and leaves beneath various species of Lauraceae and Myrtaceae in a complex notophyll vine forest of cloudy and moist to wet highlands. In Mt. Hypipamee National Park, I. hypipamee produced 50-100 basidiomata throughout the same forested slope above Dinner Falls from 16 February to 5 April 2011.

\footnotetext{
Additional collections examined: AUSTRAliA. Queensland, Cook Region, Mt. Hypipamee National Park, $17^{\circ} 25^{\prime} 35.4 S^{\prime \prime} 145^{\circ} 29^{\prime} 12.4^{\prime \prime}$ E, 14 March 2009, DL Largent 9649; $17^{\circ} 25^{\prime} 34.5^{\prime \prime} \mathrm{S} 145^{\circ} 29^{\prime} 16.6^{\prime \prime} \mathrm{E}, 16$ February 2011, DL Largent 9981, 9981A, 9982; $17^{\circ} 25^{\prime} 35.4^{\prime \prime} \mathrm{S} 145^{\circ} 29^{\prime} 10.9^{\prime \prime} \mathrm{E}, \mathrm{DL}$ Largent $9984 ; 7^{\circ} 25^{\prime} 58.6^{\prime \prime} \mathrm{S} 145^{\circ} 29^{\prime} 27.4^{\prime \prime} \mathrm{E}, 21$ February 2011, DL Largent 9988; $17^{\circ} 25^{\prime} 34.8^{\prime \prime} \mathrm{S} 145^{\circ} 29^{\prime} 17.0^{\prime \prime} \mathrm{E}, 28$ February 2011, DL Largent 9992; $17^{\circ} 25^{\prime} 37.1^{\prime \prime} \mathrm{S} 145^{\circ} 29^{\prime} 15.2^{\prime \prime} \mathrm{E}, 5$ March 2011, DL Largent 9998; $17^{\circ} 25^{\prime} 35.2^{\prime \prime} \mathrm{S}$ $145^{\circ} 29^{\prime} 14.6^{\prime \prime} \mathrm{E}, \mathrm{DL}$ Largent $9999 ; 7^{\circ} 25^{\prime} 36.7^{\prime \prime} \mathrm{S} 145^{\circ} 29^{\prime} 15.7^{\prime \prime} \mathrm{E}, 17$ March 2011, DL Largent $10035 ; 17^{\circ} 25^{\prime} 35.2^{\prime \prime} \mathrm{S} 145^{\circ} 29^{\prime} 14.6^{\prime \prime} \mathrm{E}, 29$ March 2011, DL Largent 10074; 17²5'36.7"S $145^{\circ} 29^{\prime} 15.7^{\prime \prime}$ E, 5 April 2011, DL Largent 10081; Mt. Lewis National Park, $16^{\circ} 34^{\prime} 15.3^{\prime \prime} \mathrm{S}$ $145^{\circ} 15^{\prime} 54.9^{\prime \prime}$ E, 20 March 2010, DL Largent 9804.
}

Comments - Inocephalus hypipamee is diagnosed by the mammillate, broadly conic to broadly convex to convex-campanulate pileus with dark brown tomentum in the center and dark brown fibrils and squamules elsewhere, the 


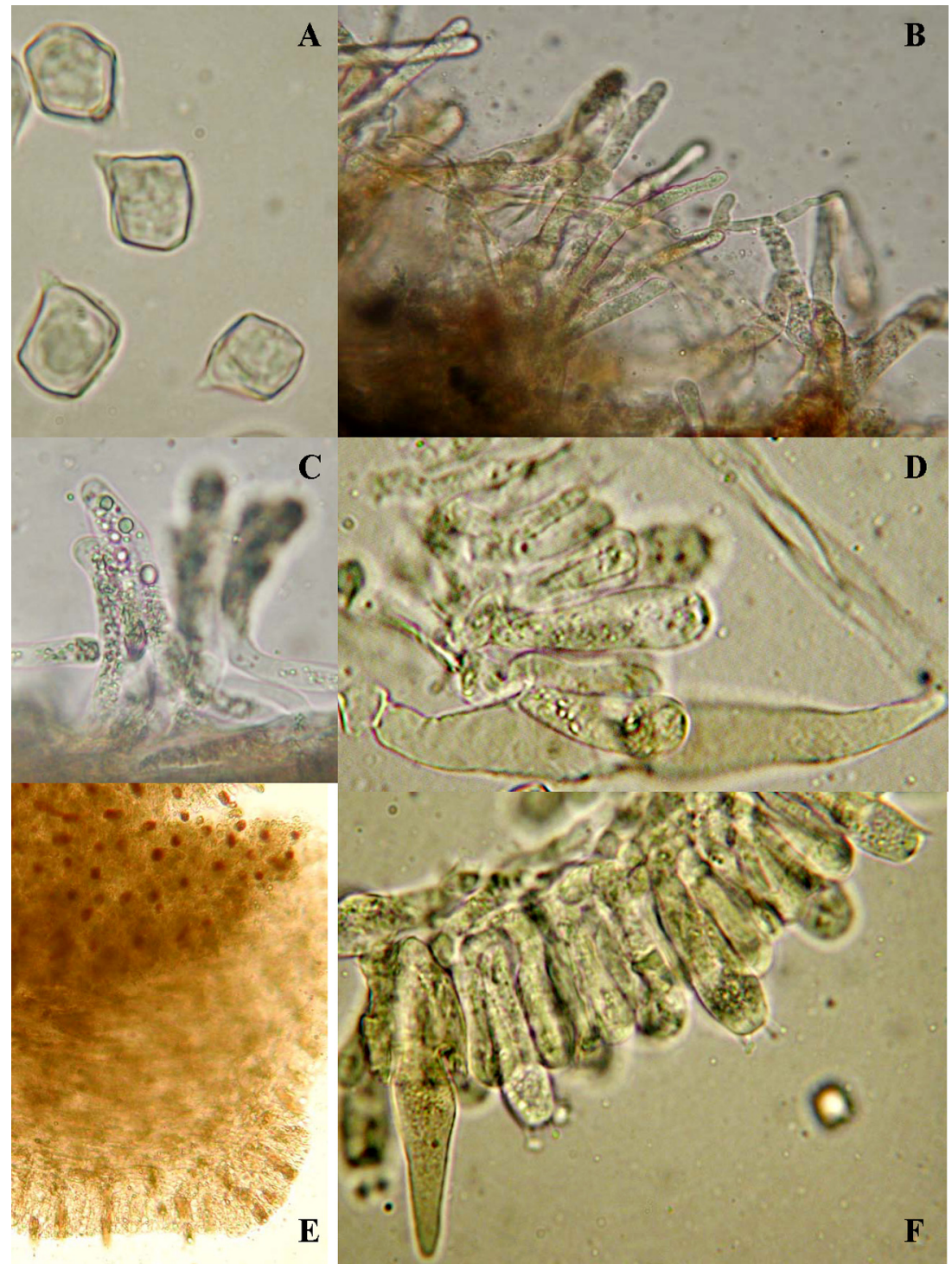

Plate 4. Inocephalus hypipamee. A: Basidiospores in profile view (1700×) (DLL 9649); B: Pileipellis composed of entangled hyphae with cylindro-clavate pileocystidia (1000x) (DLL 9988); C: Caulocystidia at apex of stipe (1000×) (DLL 9988); D: narrowly obclavate pseudocystidium originating from outer portion of lamellar trama, nearby basidioles (in focus), and mature basidium (out of focus) (150×) (DLL 9649); E: pseudocystidia on face of lamella staining reddish-brown in 3\% KOH (1000×) (DLL 9988); F: Obclavate pseudocystidium, and basidia (1000×) (DLL 9649). 
white to off-white lamellae and stipe, the cuboid to rectangular, subisodiametric basidiospores measuring 7.1-10.4 ×6.2-8.6 $\mu \mathrm{m}$, the clavate to obclavate or fusoid pseudocystidia found on the lamellar edge and face, and the absence of clamp connections.

Because of its brown pileus, white lamellae and stipe, cuboid basidiospores, pseudocystidia and absence of clamp connections, E. flavotinctum E. Horak \& Corner from Brazil is the only species remotely similar to I. hypipamee. Entoloma flavotinctum is morphologically differentiated by its smaller basidiomata, hygrophanous pileus, a stipe that becomes yellowish or greenish ochraceous, a white context that turns yellowish on cutting and bruising, and smaller quadrate basidiospores (6-8(-9) $\mu \mathrm{m}$; Horak 1982).

Inocephalus parvisporus Largent, sp. nov.

Plates 5-6

MycoBank MB 564926

Differs from Entoloma neocaledonicum by the Leptonia-like pileus with a small broad umbo in a depression, white lamellae, longer cheilocystidia, and smaller basidiospores.

TyPE - Australia, Queensland, Cook Region, Danbulla National Park, Kauri Creek Track, within $20 \mathrm{~m}$ of $17^{\circ} 07^{\prime} 42.3^{\prime \prime} \mathrm{S} 145^{\circ} 25^{\prime} 55.0^{\prime \prime} \mathrm{E}, 25$ March 2009 , DL Largent 9829 (holotype BRI, isotype CNS).

ЕтумоLоGy - from the Latin words parvi + sporus, referring to the small basidiospore size.

Pileus 10-32 mm broad, 5-15 $\mathrm{mm}$ high, when young dark brown with a reddish tinge (near $8 \mathrm{~F} 4$ ) on the disc and ornamentations with a slightly lighter dark brown (8E4) background, parabolic or campanulate-convex, or convex, entirely minutely tomentulose, and typically with a small, broad umbo and an even, incurved margin, when maturing and expanding remaining dark brown (8F4) on the disc becoming reddish white to pale red (7A-B2-3) elsewhere, becoming broadly convex to broadly campanulate-truncate with a depression developing, the umbo often disappearing, remaining tomentulose in the center becoming minutely squamulose to appressed-fibrillose towards the margin, and appressed-fibrillose at the margin, with the margin becoming decurved, crenulate-lobed and then eroded, typically opaque, at times becoming hygrophanous in the disc, not striate nor translucent-striate, dull when dry, shiny when moist. TASTE indistinct or mild. ODOR indistinct or mild. LAMELLAE 4-19 mm long, 1.75-5 mm deep, narrow then quickly moderately broad, adnate, close to subdistant, white when young with spore maturity remaining light on the edge but becoming flesh-colored elsewhere; margin smooth and concolorous, entire at all times; up to 5 lamellulae between lamellae, in 3 tiers ( 2 short, 2 medium, 1 medium long). STIPE 27-45 mm long, 1.25-4 mm broad, equal, pruinose at the apex, glabrous with hygrophanous streaks elsewhere, white $(6 \mathrm{~A} 1)$ but bruising reddish grey $(8 \mathrm{~B}-\mathrm{C} 2)$, hollow with some solidity 
Inocephalus spp. nov. (Australia) ... 315

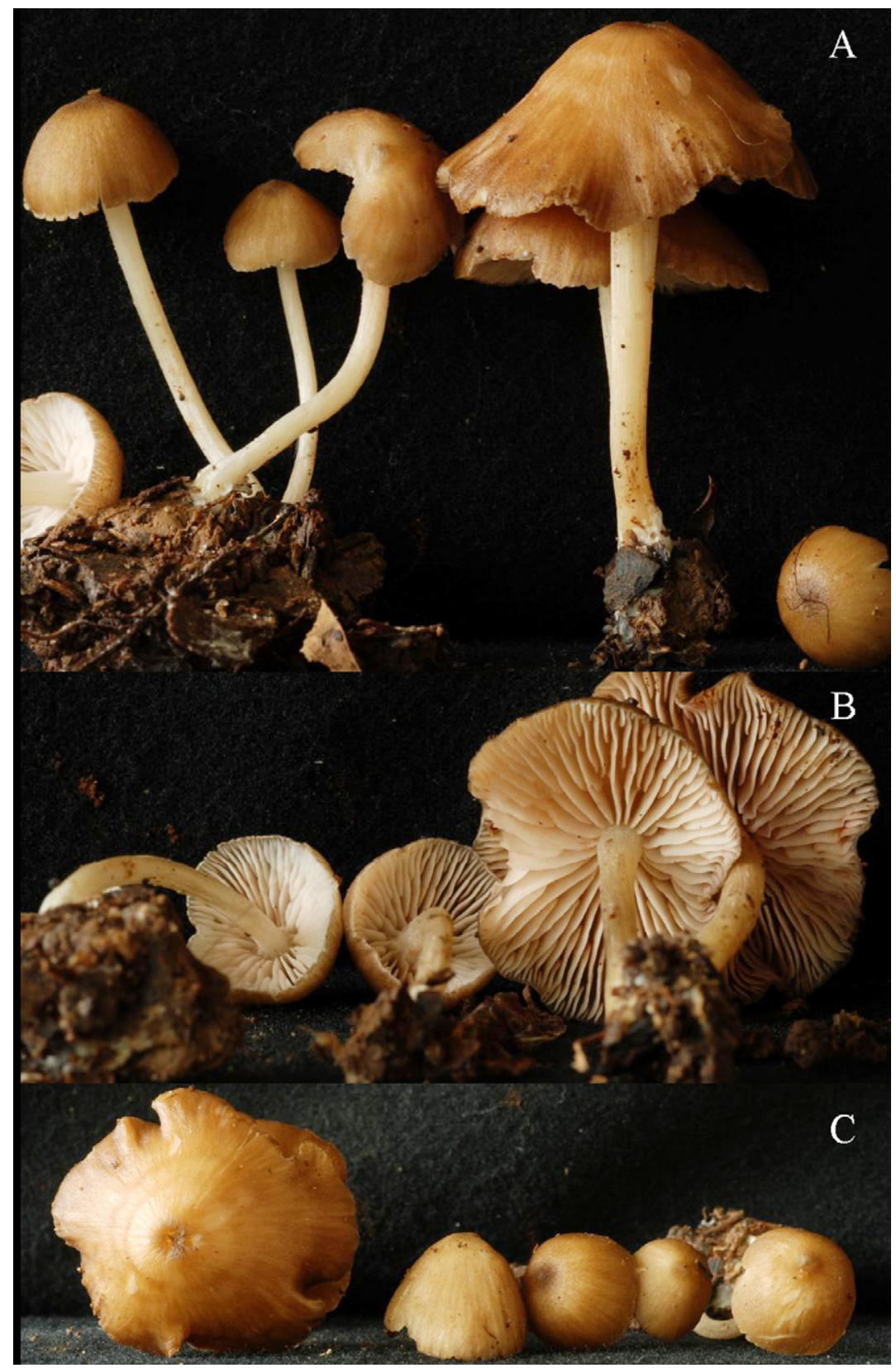

Plate 5. Inocephalus parvisporus (DLL 9829, holotype). A: Basidiomata stature (2×); B: Lamellae and pruinose stipe apex $(2 \times)$; C: Pileus surface $(2 \times)$. 


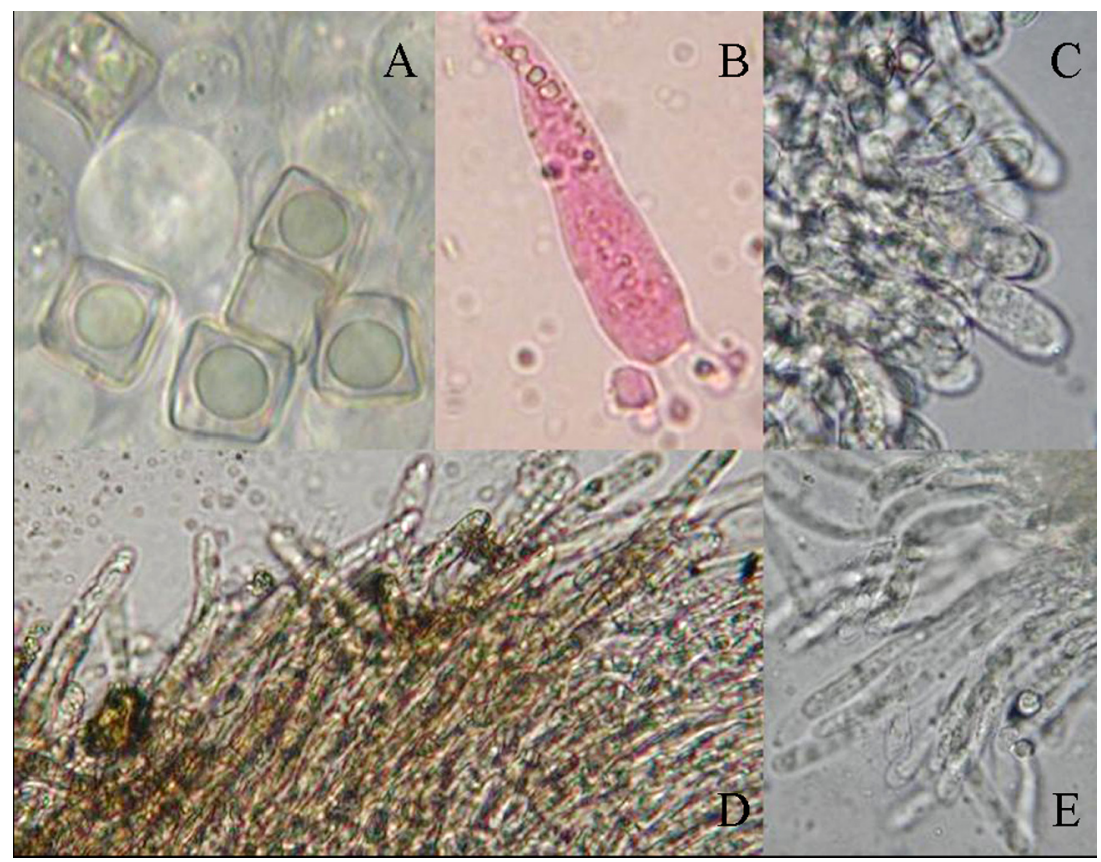

Plate 6. Inocephalus parvisporus (DLL 9829, holotype). A: Basidiospores (2700×); B: Basidium (1000x); C: Cylindro-clavate to clavate cheilocystidia (300x); D: Pileipellis just off disc with cylindro-clavate pileocystidia $(200 \times)$; E: Cylindro-clavate caulocystidia at stipe apex $(900 \times)$.

but ultimately becoming fragile; basal tomentum moderate becoming scarce. BRUISING REACTIONS absent.

BASIDIOSPORES cuboid, square to rectangular, rarely rhomboidal in profile view, 5.3-8.1 × 4.5-7.1 $\mu \mathrm{m}(x=6.5 \pm 0.6 \times 5.6 \pm 0.7 \mu \mathrm{m} ; \mathrm{E}=1.0-1.5 ; \mathrm{Q}=1.2$ \pm 0.1 (subisodiametric); $\mathrm{n}=30 / 1$ ). BAsidia clavate and tapered, 33.5-41.4 $\times$ 10.4-13.1 $\mu \mathrm{m}(x=38.9 \pm 2.3 \times 11.2 \pm 0.9 \mu \mathrm{m} ; \mathrm{E}=2.9-3.9 ; \mathrm{Q}=3.5 \pm 0.3 ; \mathrm{n}=9 / 1)$, 4-sterigmate. Aвorted basidia absent. Cheilocystidia cylindro-clavate to clavate, abundant, portions of some lamellar edge completely sterile, similar in size to the caulocystidia. Pleurocystidia and Pseudocystidia absent. Hyphae of the Lamellar trama subparallel 92.2-398.5 × 4.4-10.5 $\mu \mathrm{m}(\mathrm{n}=$ 6/1). Pileipellis a trichodermal palisade, with the hyphae erect but entangled on the disc, semi-erect and entangled towards the margin, and repent near and at the margin; Pileocystidia 48.3-148.6 × 4.9-9.3 $\mu \mathrm{m}(\mathrm{n}=6 / 1)$, long and cylindro-clavate, resembling the cheilocystidia. HyphaE of THE PILEAL TRAMA $357.8-491.3 \times 13.4-16.6 \mu \mathrm{m}(\mathrm{n}=3 / 1)$. STIPITIPELLIS with abundant cylindro- 
clavate cystidioid caulocystidia at the apex, a cutis elsewhere. CAUlocystidia clavate, similar to the cheilocystidia, 52.4-66.5 × 4.6-7.2 $\mu \mathrm{m}(\mathrm{n}=4 / 1)$. Hy PHAE OF THE STIPE TRAMA not studied. LIPOID GLOBULES abundant, particularly in the lamellar and pileal trama. Oleiferous hyphaE abundant, particularly in the lamellar and pileal trama. Brilliant granules absent. Pigmentation with dark brown cytoplasmic particles in the hyphae of the pileipellis, absent elsewhere. Clamp connections absent in all tissues.

ECOLOGY AND DISTRIBUTION - Scattered to gregarious on leaves in humus along side of Kauri Creek Track, near the end of the track as it drops down to Kauri Creek, Danbulla National Park; late March; known only from the type locality.

Comments - Unique features of Inocephalus parvisporus include its Leptonialike habit and basidiomata with dark brown, umbonate, opaque pilei with slight reddish tones, the small basidiospores, the presence of cheilocystidia, small cuboid basidiospores, and no clamps. In the field, it resembles a species of Leptonia (Fr.) P. Kumm., although the abundant oleiferous hyphae, abundant lipoid bodies, and cuboid basidiospores suggest Inocephalus.

Because of their brown basidiomata and cuboid basidiospores, Entoloma griseoalbum E. Horak from Papua New Guinea and E. neocaledonicum E. Horak from New Caledonia share similar morphological features with I. parvisporus. However, both E. neocaledonicum and E. griseoalbum are morphologically differentiated by their mycenoid basidiomata with a conical pileus. In addition, E. griseoalbum has a grey brown striate pileus and clavate cheilocystidia often with finger-like protrusions, and E. neocaledonicum has pale wax yellow lamellae, broadly clavate cheilocystidia, larger basidiospores, and clamp connections (Horak 1976, 1977).

\section{Acknowledgments}

Fieldwork in Australia was supported by the Largent family trust and we are particularly grateful for the support of Pamela Largent. Fieldwork and logistical support were provided by the Australian Tropical Herbarium and the School of Marine and Tropical Biology, James Cook University. The DNA sequences generated in this study are based upon work supported by the National Science Foundation under Grant No. DRI 0922922 awarded to SE Bergemann. Comments by the two reviewers, Dr. Timothy J. Baroni and Dr. Genevieve Gates, and by the nomenclature editor Dr. Shaun Pennycook, were also helpful. We wish to thank Peter Newling for sharing his collections from northern Queensland and for providing the identification of vascular plants and habitat descriptions for taxa collected in Mt. Hypipamee National Park, and Pam O'Sullivan as well as Skye Moore for sharing their collections and descriptions from New South Wales. We also wish to thank Dr. Baroni for information provided of his type study of Agaricus cuspidatus and the identification of Inocephalus luteus. 


\section{Literature cited}

Baroni TJ, Halling RE. 2000. Some Entolomataceae (Agaricales) from Costa Rica. Brittonia 52: 121-135. http://dx.doi.org/10.2307/2666502

Baroni TJ, Matheny PD. 2011. A re-evaluation of gasteroid and cyphelloid species of Entolomataceae from Eastern North America. Harvard Papers in Botany 16: 293-310. http://dx.doi.org/10.3100/0.25.016.0205

Baroni TJ, Hofstetter V, Largent DL, Vilgalys R. 2011. Entocybe is proposed as a new genus in the Entolomataceae (Agaricomycetes, Basidiomycota) based on morphological and molecular evidence. North American Fungi 6: 1-19.

Berkeley MJ, Curtis MA. 1859. Centuries of North American fungi. Annals and Magazine of Natural History, Series 3, 4: 284-296.

Co-David D, Langeveld D, Noordeloos ME. 2009. Molecular phylogeny and spore evolution of Entolomataceae. Persoonia 23: 147-176. http://dx.doi.org/10.3767/003158509X480944

Eyssartier G, Buyck B, Courtecuisse R. 2001. New species and combinations in cuboid-spored Entoloma species from Madagascar. Mycological Research: 105: 1144-1148. http://dx.doi.org/10.1016/S0953-7562(08)61979-6

Eyssartier G, Ducousso M, Buyck B. 2010. Entoloma pseudomurrayi sp. nov., a nouvel entolome jaune des forêts nêo-calêdoniennes de montagne à Nothofagus. Cryptogamie Mycologie 31: $3-8$.

Hesler LR. 1963. A study of Rhodophyllus types. Brittonia 15: 324-366. http://dx.doi.org/10.2307/2805380

Hesler LR. 1967. Entoloma in southeastern North America. Beihefte zur Nova Hedwigia 23: $1-196$.

Horak E. 1976. On cuboid-spored species of Entoloma (Agaricales). Sydowia 28:171-236.

Horak E. 1977. Entoloma in South America I. Sydowia 30: 40-111.

Horak E. 1980. Entoloma (Agaricales) in Indomalaya and Australasia. Beihefte zur Nova Hedwigia 65: 1-352.

Horak E. 1982 Entoloma in South America II. Sydowia. 35: 75-99.

Kornerup A, Wanscher JH. 1978. Methuen handbook of colour 3rd ed. Richard Clay Ltd: Chichester, Sussex.

Largent DL. 1994. Entolomatoid fungi of the western United States and Alaska. Mad River Press Inc: Eureka, California

Largent DL, Abell-Davis SE. 2011. Observations on Inocephalus virescens comb. nov. and Alboleptonia stylophora from northeastern Queensland. Mycotaxon 116: 231-245. http://dx.doi.org/10.5248/116.231

Largent DL, Abell-Davis SE, Cummings GA, Ryan KL, Bergemann SE. 2011a. Saxicolous species of Claudopus (Agaricales, Entolomataceae) from Australia. Mycotaxon 116: 253-264. http://dx.doi.org/10.5248/116.253

Largent DL, Bergemann SE, Cummings GA, Ryan KL, Abell-Davis SE, Moore S. 2011b. Pouzarella (Agaricales, Entolomataceae) from New South Wales (Barrington Tops National Park) and northeastern Queensland. Mycotaxon 117: 435-483. http://dx.doi.org/10.5248/117.435

May TW, Wood AE. 1997. Catalogue and bibliography of Australian macrofungi 1. Basidiomycota. Fungi of Australia Vol. 2A. Australian Biological Resources Study: Canberra.

Noordeloos ME. 1992. Entoloma s.l. in Fungi Europaei vol. 5. Ed. Candusso: Alassio, Italy. Noordeloos ME. 2004. Entoloma s.l. in Fungi Europaei vol. 5A. Ed. Candusso: Alassio, Italy.

Noordeloos ME. 2008. Entoloma in North America 2: the species described by C. H. Peck - type studies and comments. Österreichische Zeitschrift für Pilzkunde 17: 87-152. 
Noordeloos ME., Gates, GM. 2012. The Entolomataceae of Tasmania. Fungal Diversity Research Series 22: 1-399. http://dx.doi.org/10.1007/978-94-007-4679-4.

Peck CH. 1872. Report of the Botanist. Annual Report of the New York State Museum of Natural History 24: 41-108.

Pegler DN, Young TK. 1978. Entolomataceae Kotl. \& Pouz. World Pollen Spore Flora 7: 1-32.

Ratkowsky DA, Gates GM. 2002. A preliminary census of the macrofungi of Mount Wellington, Tasmania - the Agaricales. Papers and Proceedings, Royal Society Tasmania 136: 89-100

Romagnesi H. 1941. Les Rhodophylles de Madagascar (Entoloma, Nolanea, Leptonia, Eccilia, Claudopus). Prodrome à une Flore Mycologique de Madagascar et Dépendances 2: 1-164.

Singer R. 1942. Type studies on Agarics. Lloydia 5: 97-135.

Thiers B. 2012 [continuously updated]. Index Herbariorum: A global directory of public herbaria and associated staff. New York Botanical Garden's Virtual Herbarium.

http://sweetgum.nybg.org/ih/ [accessed May 2012]

Young AM. 2005. A field guide to the fungi of Australia. University of South Wales Press: Sydney. 